\title{
Do cholecystectomy rates correlate with geographic variations in the prevalence of gallstones?
}

\author{
KLIM MCPHERSON, ${ }^{1}$ P M STRONG, ${ }^{*}$ LESLEY JONES, ${ }^{1}$ AND B J BRITTON ${ }^{2}$ \\ From the Department of Community Medicine and General Practice, ${ }^{1}$ Radcliffe Infirmary, Oxford and \\ Department of Surgery, ${ }^{2}$ John Radcliffe Hospital, Oxford
}

SUMmARY Two fold variations in the age and sex standardised post mortem prevalence of gallstones have been demonstrated between nine British towns by Barker and his colleagues. We have examined the rates of cholecystectomy in the Districts serving seven of these towns to discover whether the incidence of operation bears any relation to this variation in morbidity. The opportunity to compare independent measurements of morbidity with the supply of health services and their use is rare, and in this example a plausible association is demonstrated. Variations in cholecystectomy rates between countries is, however, more difficult to explain by variations in relevant morbidity.

Large differences in the rates of cholecystectomy have been documented. Bunker ${ }^{1}$ and Vayda ${ }^{2}$ show three to four fold differences in the use of this operation between North America and England and Wales. Whether such differences can be attributed wholly to differences in morbidity is not known. ${ }^{3}$ In a recent study, McPherson et al ${ }^{4}$ noted that of eight common 'discretionary' operations the one with least variation between Regional Health Authorities was cholecystectomy. Cholecystectomy also exhibited the lowest correlation with indices of health care supply, such as numbers of general surgeons, surgical beds, general practitioners or overall funding relative to Resource Allocation Working Party (RAWP) targets. More detailed analysis of the variations in the rates of common operations between neighbouring hospital service areas demonstrated ${ }^{5}$ that cholecystectomy had a low variation between such areas and that the amount of relative variation was very similar in Norway, England and Wales, and the US. Therefore, it has fewest charactersitics associated with 'discretionary' procedure and is likely to be associated with unpredicted but systematic differences in population morbidity.

In the context of prevailing cynicism about the nature and role of medical care ${ }^{6}$ and debate about the indications for cholecystectomy, ${ }^{7}$ we thought it important to investigate the association between

*Present address: Biology Discipline, Open University, Milton Keynes MK7 6AA. crude but independent indices of need and health service use. While supply and utilisation of health care facilities are generally easy to measure, other important facets of the health care system, such as need or morbidity, are not ${ }^{8}$ and consequently tend to be omitted from any analysis attempting to explain observed variations. ${ }^{9}$

The paper by Barker et $a l^{10}$ provides an opportunity to test the hypothesis that surgical care in the National Health Service relates to illness as well as possibly to demand or supply. Their study, based on nine towns in England and Wales, measured the prevalence of gallstones among some 5,000 necropsies over an 18 month period. The towns were stratified by latitude and socioeconomic conditions.

The test adopted here is not as sensitive as one might have wished because absence of an empirical association could still be attributed to the crudeness of the measures. The prevalence of gallstones in a population may not be measured adequately by the prevalence at necropsy. The presence of gallstones is not always a sufficient indication for surgery."1 Cholecystectomy is justified once a major complication such as acute cholecystitis or obstructive jaundice has developed. However, surgery for symptoms of intermittent indigestion or epigastric pain is more discretionary. Finally, truly silent gallstones discovered by accident arouse great controversy. Some surgeons consider that they should be removed. ${ }^{12}$ However, a recent study of the 
natural history of silent gallstones noted relevant symptoms in only $18 \%$ even after 15 years of follow up. ${ }^{13}$

\section{Methods}

The data of Barker et al, based on necropsies carried out between January 1977 and May 1978, provided information on morbidity. We obtained Hospital Activity Analysis (HAA) data for the Districts of seven of the towns covered in the study by Barker $e t$ al. One District wanted to charge for the information, and for another the data were not available. The number of cholecystectomies performed in a three year period between 1965 and 1978 were kindly supplied by the relevant Regional Health Authorities and covered all operations performed in the appropriate District. We obtained data relating to the number of general surgeons, the number of available surgical beds, and the allocated surgical beds for the period in question.

Unfortunately, HAA data omit private surgery, and in consequence our data underestimate the total amount of gallbladder surgery by an unknown amount. Population data on the Districts were provided from Office of Population Censuses and Surveys estimates. Because we are comparing utilisation with supply and morbidity within Districts, and not between them, it is not necessary to standardise for differences in the age and sex structure of Districts. Crude figures are, therefore, used throughout this paper.

\section{Results}

We first examined the effect of variations in population based rates of consultant general surgeons (whole time equivalents) and available surgical beds (the relation of allocated beds was similar to that for available beds). The variables had in one case a negative and in the others a zero association with cholecystectomy rates (table). Very similar to that for available beds). The variables had gallstones. The higher the prevalence of gallstones, the lower the number of consultant general surgeons and available beds per 1000 population in these Districts. However, none of these correlations approached statistical significance. We might therefore tentatively conclude, since it was such a small sample, that these aspects of the supply of surgical facilities are neither affected by this measure of prevailing morbidity nor affect the rate of cholecystectomy.

If we look, however, at the relation between the prevalence of gallstones and the use of cholecystectomy we find a strong positive association
Correlation coefficients of prevalence of gallstones with indices of health care supply and cholecystectomy rates

\begin{tabular}{lllc}
\hline & $\begin{array}{l}\text { General } \\
\text { surgeons }\end{array}$ & $\begin{array}{l}\text { Available } \\
\text { beds }\end{array}$ & Cholecystectomy \\
\hline $\begin{array}{l}\text { Prevalence of } \\
\text { gallstones }\end{array}$ & -0.39 & -0.27 & 0.75 \\
$\begin{array}{l}\text { Consultant } \\
\text { general surgeons } \\
\text { per } 1000 \text { population }\end{array}$ & - & 0.91 & -0.18 \\
$\begin{array}{l}\text { Available } \\
\text { surgical beds } \\
\text { per } 1000 \text { population }\end{array}$ & - & - & 0.04 \\
\hline
\end{tabular}

$(r=0.75, p=0.05)$. The towns with the lowest and highest prevalence of gallstones are in the Districts with, respectively, the lowest and highest cholecystectomy rates. Adjusting for differences in supply made little difference to the relationship.

\section{Discussion}

Variations in use rates between hospital service areapi or Districts are generally taken as a measure largel $\vec{W} \vec{v}$ of the role of clinical discretion in determining the chance of hospitalisation but only when these 9 Districts are relatively homogeneous in terms of the $\vec{c}$ populations served and the supply of hospitad services. Thus many studies of small area variation $\frac{1}{10}$ have concluded that discretion or clinical uncertaint $\vec{E}$ play an important role in determining the or hospitalisation rates for diagnoses or procedures which exhibit large variations between neighbouring Districts in a single Region. ${ }^{14}$ Cholecystectomy rates do not vary very much between such Districts, although they do vary between countries. In this study, we are comparing the variation in cholecystectomy rates across Districts that are widely dispersed across England and Wales and therefore for which there is no reason to suppose that the populations served or the supply of services are at all similar. The supply of services, at least as measured, appear to play no part in determining these different cholecystectomy rates. It does seem, however, that independent measures of relevant population morbidity are associated with cholecystectomy rates. Our findings are therefore a reasssuring reflection on $₹$ the ability of the National Health Service to respond $\frac{9}{9}$

to differences in need.
Barker's data suggest that about $20 \%$ of elderly people (the average age of his sample was 68 years) $N$ currently have gallstones detected at necropsy with a $\sigma$ greater proportion in women and an increasing $N$ prevalence with age. In contrast, if we assume current $\underset{\omega}{N}$ rates of cholecystectomy, between $7 \%$ and $16 \%$ of the 0 
population studied here should have had a cholecystectomy by the age of $65 . .^{15}$ Holland and Heaton ${ }^{16}$ estimated, however, that the cholecystectomy rate increased $3 \frac{1}{2}$-fold in Bristol between 1940 and 1970 and, assuming that this increase is similar throughout the country, we could expect the prevalence of cholecystectomy at necropsy among the elderly now to be between $2 \%$ and $5 \%$. In fact, Barker found an overall $2 \%$ prevalence of cholecystectomy, ranging from $1 \%$ to $4 \%$ in the nine towns. ${ }^{17}$ Thus at present about one patient in ten with gallstones has had a cholecystectomy before death (assuming all cholecystectomy is for cholelithiasis). So nine patients apparently have had insufficient symptoms to result in surgery. This does not, of course, necessarily mean that all the stones are completely symptomless. As the present population ages, however, 20\% will develop gallstones and around $10 \%$ of these will have a cholecystectomy.

Is there a growing general awareness of illness or have patients in the past been dissuaded from complaining, or has the disease prevalence been increasing? ${ }^{18}{ }^{19}$ Surgeons have probably relaxed the indications for surgery as the operation has become safer, but it seems unlikely that improved investigations have discovered more stones, for cholecystography has been available for over 50 years now, and its accuracy has not materially changed. More recently, ultrasound imaging of the gallbladder has been introduced, and although its accuracy is similar to that of cholecystography it is probably better able to demonstrate small stones, ${ }^{20}$ and improved diagnosis may therefore become a factor in future increases in cholecystectomy rates.

There still remains, however, the fact that the standardised rate of cholecystectomy in England and Wales is one third of that in the USA and one quarter of that in Canada. ${ }^{4}$ Since two fold variations in the prevalence of gallstones within the United Kingdom can be observed then equivalent variations between nations could plausibly explain these differences in cholecystectomy rates. However, Opit and Greenhall ${ }^{21}$ compared the prevalence of gallstones at necropsy in four countries, including the USA and Great Britain, derived from series obtained during the first half of this century. The prevalence in all age groups except the youngest was lower in the USA. They concluded that different cholecystectomy rates could not therefore be taken to be a reflection of different prevalence rates. Since Brett and Barker ${ }^{22}$ also did not find any recent evidence for an excess of gallstones at necropsy in North America, one must assume that other factors determine these international differences.
The most plausible ones would seem to be differences in the prevailing rates of clinical, radiological, and ultrasound investigation and different clinical indications for the operation. Comparing the variations in the use of cholecystectomy between neighbouring hospital service areas in the three countries, McPherson et al $^{5}$ found that the relative variation within countries was the same. This suggests that a different aggregate clinical threshold is being applied to a similar level of population morbidity. Part of the explanation for different clinical thresholds could be attributed to a higher use of screening for silent gallstones with a view to prophylactic surgery.

Three points may be made in conclusion. The first concerns the reasons for this international difference in clinical consensus. Is the difference in gallbladder surgery rates a manifestation of differences in structural incentives? In the face of clinical uncertainty, does economic shortage dictate conservative management where fee-for-service medicine and third party insurance encourage intervention? ${ }^{23}$ Secondly, the data reported here suggest that the clinical threshold in the National Health Service is sufficiently uniform to enable operation rates to show a plausible relation with measurable morbidity. Therefore, since the differences between the USA and the UK are probably largely the product of consistent but different indications for cholecystectomy, the next major step in research would be to conduct randomised prospective studies to demonstrate the relative advantages and disadvantages of each approach.

Lastly, of course, this analysis (perhaps for the first time) demonstrates a consistent relation between an independent measure of morbidity and relevant health service utilisation. The all too simple assumption, often made when large variations exist in hospital utilisation rates, that these variations are necessarily attributable to variations in supply of services is contradicted by these data. Therefore such an assumption should generally only be made with caution.

\section{References}

${ }^{1}$ Bunker JP. Surgical manpower: a comparison of operations and surgeons in the United States and in England and Wales. New Engl J Med 1970, 282: 135-9.

${ }^{2}$ Vayda E. A comparison of surgical rates in Canada and in England and Wales. New Engl J Med 1973, 289: 1224-34.

${ }^{3}$ Plant JCD, Dency I, Bates T, Gastard J, de Nercy YH. Incidence of gallbladder disease in Canada, England and France. Lancet 1973 ii: 249-51. 
${ }^{4}$ McPherson K, Strong PM, Epstein A, Jones L. Regional variations in the use of common surgical procedures within and between England and Wales, Canada and the United States of America Soci Sci \& Med 1981 15A, 273-88.

${ }^{5}$ McPherson K, Wennberg JE, Hoving OB, Clifford P. Small area variations in the use of common surgical procedures: an international comparison of New England, England and Norway New Engl J Med 1982, 307; $1310-4$.

${ }^{6}$ Illich I. Limits of medicine, medical nemesis: the expropriation of health Pelican Books 1977.

${ }^{7}$ Fitzpatrick G, Neutra R, Gilbert J. Cost effectiveness of cholecystectomy for silent gallstones. In: Bunker $\mathrm{K}$, Barnes B, Mosteller F, eds Costs, risks and benefits of surgery. Oxford University Press. 1977.

${ }^{8}$ Fenton Lewis A. Morbidity data: what do we have? What do we need? What are we likely to get? Health Trends 1979 2; Vol. 11: 49-50.

${ }^{9}$ Wennberg JE, Barnes BA, Zubkoff M. Professional uncertainlty and the problem of supplier-demand Soci Sci \& Med 1982, 16; 811-24.

${ }^{10}$ Barker DJP, Gardner MJ, Power C, Hutt MSR. Prevalence of gallstones in nine British towns: a collaborative study. $\mathrm{Br} \mathrm{Med} J \mathrm{1979}$, 1389-92.

${ }^{11}$ Bouchier IAD. Brides of quietness: silent gallstones $\mathrm{Br}$ Med J 1983, 286: 415-6.
${ }^{12}$ Anon. Dangers of silent gallstones. $\mathrm{Br} \mathrm{Med} J$, i: 415 .

${ }^{13}$ Gracie WA, Rensohoff DF. The natural history of silent gallstones. The innocent gallstone is not a myth. New Engl J Med 1982, 307, 798-800.

${ }^{14}$ Wennberg JE, McPherson K, Caper P. Will payment based on diagnosis-related groups control hospital costs. New Engl J Med 1984, 311, 295-300.

${ }^{15}$ Gittelsohn AN, Wennberg JE. On the risk of organ loss. $J$ Chron Dis 1976, 29: 527-35.

${ }^{16}$ Holland $\mathrm{C}$, Heaton $\mathrm{KW}$. Increasing frequency of gallbladder operations in the Bristol clinical area $\mathrm{Br} \mathrm{Med}$ J 1972, 3: 672-5.

${ }^{17}$ Barker DJP. Personal communication.

${ }^{18}$ Bateson MC. Gallbladder disease and cholecystectomy rates are independently variable Lancet 1984, ii; 621-4.

${ }^{19}$ McPherson K, Strong $\mathrm{P}$, Jones L, Britton J. Lancet 1984; ii: 1092.

${ }^{20}$ Cooperberg PL, Burhenne HJ. Real-time ultrasonography. Diagnostic technique of choice in 0 calculous gallbladder disease. New Engl J Med 1980, ص 302; 1277-9.

${ }^{21}$ Opit LJ, Greenhill S. Prevalence of gallstones in relation $\vec{\circ}$ to differing treatment rates for biliary disease. $\mathrm{Br} \mathrm{J} \mathrm{Prev}$ Soc Med 1974, 28: 268-72.

${ }^{22}$ Brett M, Barker DJP. the world distribution of gallstones Int $J$ Epidemiol 1976, 5: 335-41.

${ }^{23}$ Anon. Ethics and the nephrologist. Lancet 1981, i: 594-6. 